\title{
The Impact of Timing of Surgery and the Anesthesia Technique in Hip Fracture Surgery on In-hospital Mortality and Length of Hospital Stay
}

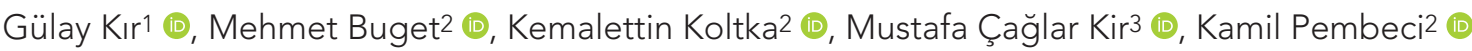 \\ ${ }^{1}$ Koç University Hospital, Department of Intensive Care Unit, İstanbul, Turkey \\ ${ }^{2}$ Istanbul University, Istanbul Faculty of Medicine, Department of Anesthesiology and Intensive Care, İstanbul, Turkey \\ 3University of Health Sciences Turkey, Okmeydanı Training and Research Hospital, Department of Orthopedics and Traumatology, İstanbul, Turkey
}

Cite this article as: Kır G, Buget M, Koltka K, Kir MÇ, Pembeci K. The Impact of Timing of Surgery and the Anesthesia Technique in Hip Fracture Surgery on Inhospital Mortality and Length of Hospital Stay. JAREM 2020;10(1): 82-7

\begin{abstract}
Objective: To point the positive impact of early surgery (performed within 48 hours) and non-general anesthesia techniques on early outcomes like inhospital mortality and length of hospital stay (LOS).

Methods: Seven hundred and ten patients were included in this retrospective study. Patients aged 50 years and over, who were admitted to our hospital with hip fracture, were included, while the patients with pathological fractures or polytraumatic injuries were excluded.

Results: The median age of the patients was $75.8 \pm 10,3$ years. Four hundred and sixty-nine (66.1\%) patients were female. Six hundred and eighty-two patients $(96.1 \%)$ were treated surgically, 16 patients $(2.25 \%)$ received conservative treatment and 12 patients $(1.7 \%)$ died before scheduled surgery. General anesthesia $(n=328)$, spinal anesthesia $(n=268)$, unilateral spinal anesthesia $(n=47)$, peripheral nerve block $(n=29)$, and combined spinal-epidural (CSE) anesthesia $(n=10)$ were the anesthesia techniques used for surgery. Patients who were treated within 48 hours (G1) had lower in-hospital mortality than the patients who were treated lately (G2) (0.8\% vs $4,7 \%$ ). The LOS for G1 was 8.6 days whereas it was 17.5 days for $G 2$ ( $p<0.001)$. Mortality rates and median LOS of the anesthesia techniques were $5.5 \%$ and 15 days with general anesthesia, $2.2 \%$ and 14 days with spinal, and $4.3 \%$ and 13 days with unilateral spinal anesthesia. There were no deaths in 10 patients with 11.5 days of LOS, who received CSE anesthesia, while the mortality rate of the peripheral nerve block group was $3.4 \%$ with 10 days of LOS.

Conclusion: The results of this study suggest that the surgical repair of the fractured hip should be performed within the first 48 hours, with a non-general anesthesia technique in order to reduce in-hospital mortality and LOS.
\end{abstract}

Keywords: Hip fracture, mortality, length of stay, timing of surgery, anesthesia technique

\section{INTRODUCTION}

Hip fractures are the most common osteoporotic fractures with serious consequences in elderly population. Across the world, the prevalence of hip fractures is $1.6 \%$ at the age of 65 years and it increases to $8.9 \%$ for individuals older than 90 years (1). Considering the increased lifetime expectancy, these numbers are expected to increase to 2.6 million by the year 2025 and to
4 million by the year 2050 while it was only 1.26 million in the year 1990 (2). Hip fracture impairs the physical function and may lead to loss of independency, thus has a high impact on quality of life along with the consumption of healthcare resources $(3,4)$. Despite the advances in anesthesia and surgical techniques, and perioperative nursing care, hip fractures are still associated with high morbidity and mortality rates and one of the most common 
causes of death with trauma, cardiovascular disease and cancer in the elderly population (5). Consequently, this devastating medical problem has become one of the major issues in healthcare systems. The literature about early and one-year mortality in hip fracture patients is very rich (6-11). One-year mortality rates of hip fracture for all age groups have been reported between $12 \%$ and $36 \%$ in different studies and up to $50 \%$ in extremely older patients (8-12).

Aging of the population, so do the hip fracture patients', causes additional medical problems in acute management of the hip fracture patients. Most of the hip fracture patients undergo surgery and a typical hip fracture patient is confined to bed-rest before surgery. Delay in surgery may cause an increase in the incidence of bed-rest associated complications including atelectasis, thromboembolism, pneumonia, urinary tract infections, pressure sores and delirium, which may increase in the length of hospital stay (LOS) (13). On the other hand, delaying surgery until physiological stabilization will let more time for the correction of dehydration, electrolyte imbalance, anemia and uncontrolled hypertension, arrhythmias, control of hemorrhagic risks in patients taking anticoagulants or antiplatelet agents, uncontrolled diabetes mellitus or treatment of co-existing infections. Although the recent studies suggest early surgery, optimal time of surgical repair of the fractured hip is still one of the most controversial questions in the hip fracture management $(7,14,15)$.

The aim of the present study was to evaluate the impact of timing of surgery and type of anesthesia for surgical treatment of fractured hip on in-hospital mortality and LOS.

\section{METHODS}

This retrospective study comprised of patients with a primary diagnosis of hip fracture, who were admitted to İstanbul University, İstanbul Faculty of Medicine, Department of Orthopedics and Traumatology between January 2004 and December 2010.Ethical Committee approval was obtained from Gaziosmanpaşa Taksim Training and Research Hospital (approval number: 2011/809-569). Patients younger than 50 years, patients with pathologic fractures, distal or femoral shaft fractures, bilateral fractures, and multiple trauma patients were excluded.

Seven hundred and ten patients' information including age, gender, discharge diagnoses and procedure codes according to the International Classification of disease-10, time to surgery, LOS and in hospital mortality rates were derived retrospectively from hospital records. Type of treatment [conservative treatment, minimally invasive surgery, open reduction-internal fixation (ORIF) or arthroplasty], type of anesthesia performed during the surgery (general anesthesia, spinal, unilateral spinal, combined spinalepidural (CSE) anesthesia, peripheral nerve block), and time of surgery were also recorded using a standardized case report form. Mortality was considered as in-hospital mortality. Post-discharge mortality rates ( 3 months, 6 months and 1 year) were not included.
This is a retrospective research; therefore, informed consent was not obtained from the patients.

\section{Statistical Analysis}

Number Cruncher Statistical System 2007 \& Power Analysis and Sample Size 2008 Statistical Software (Utah, USA) program was used for statistical analyses. Student's t-test was used for the comparison of quantitative data and normally distributed parameters as well as the descriptive statistical methods (mean value, standard deviation, median, frequency, ratio) for the evaluation of the collected data. Mann-Whitney $U$ test and Kruskall-Wallis tests were performed for the two and three group comparisons of the abnormally distributed parameters, respectively. Mann-Whitney $U$ test was also used for the determination of the group responsible for the difference. Pearson chi-square test was performed to compare qualitative data. Fisher's Exact and Yates Continuity Correction tests were used for the determination of the group that makes the difference. Finally, Spearman's Correlation Analysis was used to assess the correlation between the parameters. Statistical significance levels were $p<0.01$ and $p<0.05$.

\section{RESULTS}

$66.1 \%(n=469)$ of the patients were female. The age of the patients ranged between 50 and 109 years (mean $75.8 \pm 10.3$ years). One hundred thirty of 682 patients $(19.06 \%$ ) received surgical treatment within 48 hours from the admission (group 1) while 552 patients (80.94\%) waited more than 48 hours for the surgery (group 2). Surgical fixations were performed between the day of admission and the $28^{\text {th }}$ day (mean: $6.12 \pm 412$ days) while LOS ranged between 2 and 138 days (mean: $15.63 \pm 10.23$ days) $54.1 \%$ of the patients $(n=384)$ had intertrocanteric fractures, 36.1\% $(n=256)$ had femoral neck fractures, and $9.9 \%(n=70)$ of the patients had subtrocanteric fractures. Twenty-eight patients (3.9\%) were treated conservatively. Surgically treated 682 patients' (96.1\%) treatment modalities were given as follows: $63.9 \%(n=436)$ had arthroplasty, $32.4 \%(n=221)$ of the patients were treated with closed reductioninternal fixation (CRIF) technique, and $3.7 \%(n=25)$ were treated with ORIF technique. General anesthesia 48.1\% ( $n=328)$, spinal anesthesia $39.3 \% \quad(n=268)$, unilateral spinal anesthesia $6.9 \%$ $(n=47)$, peripheral nerve block $4.2 \%(n=29)$ and CSE anesthesia $1.5 \%(n=10)$ were the techniques performed for surgery. Mortality rates in patients whose surgery were delayed for more than 48 hours were significantly higher than the patients who had surgery within 48 hours $(p<0.05)$. LOS was also significantly longer in this group $(p<0.01)$ (Table 1).

Total in-hospital mortality rate of the 710 patients was $5.1 \%$ $(n=36)$. The in-hospital mortality rate of the patients who had surgery was $3.4 \%(n=24)$ while $1.7 \%$ of the patients $(n=12)$ died before the surgery. Statistically significant result was obtained when the effects of general and regional anesthesia techniques were compared with respect to in-hospital mortality $(p=0.049$; $p<0.05$ ) (Table 2). However, there were no statistically significant 
differences between the regional anesthesia techniques when compared $(p>0.05)$.

LOS of different anesthesia technique groups was significantly different $(p=0.001 ; p<0.01)$. The general anesthesia group had longer LOS than the spinal, peripheral nerve block and unilateral spinal anesthesia groups $(p=0.009 ; p=0.001 ; p=0.005 ; p<0.01)$ (Table 3). Hospitalization was longer in the spinal anesthesia group than the peripheral nerve block group $(p=0.004 ; p<0.01)$. There was no statistically significant difference between LOS when the other anesthesia techniques were compared ( $p>0.05$ ).

There was a strong correlation with $32.4 \%$ positive ratio (hospitalization lengthens with increased age) between age and LOS ( $r=0.324 ; p<0.01$ ) (Table 4) (Figure 1). There was also a strong correlation with $23.8 \%$ positive ratio (operation is delayed

\begin{tabular}{|c|c|c|c|}
\hline & \multicolumn{2}{|c|}{ Timing of the operation } & \multirow[b]{2}{*}{$p$} \\
\hline & $\begin{array}{l}\leq 48 \text { hours } \\
(n=130)\end{array}$ & $\begin{array}{l}>48 \text { hours } \\
(n=552)\end{array}$ & \\
\hline $\begin{array}{l}\text { ¿LOS; Mean } \pm \text { SD } \\
\text { (median) }\end{array}$ & $8.62 \pm 3.74(8.0)$ & $\begin{array}{l}17.55 \pm 10.51 \\
(16.0)\end{array}$ & ${ }^{a} 0.001$ ** \\
\hline Mortality; n (\%) & $1(0.8 \%)$ & $26(4.7 \%)$ & b0.043* \\
\hline
\end{tabular}

Table 2. Evaluation of the mortality rates according to different anesthesia modalities

\begin{tabular}{|c|c|c|}
\hline Anesthesia modality $(n=682)(\%)$ & $\begin{array}{l}{ }^{\text {a Mortality }} \\
(n=36) ;(\%)\end{array}$ & ${ }^{a} p$ \\
\hline \multicolumn{3}{|l|}{ General } \\
\hline $328(48.1 \%)$ & $18(5.5 \%)$ & $0.049 *$ \\
\hline \multicolumn{3}{|l|}{ Regional } \\
\hline $354(51.9 \%)$ & $9(2.5 \%)$ & - \\
\hline \multicolumn{3}{|l|}{ Bilateral spinal } \\
\hline $268(39.3 \%)$ & $6(2.2 \%)$ & - \\
\hline \multicolumn{3}{|l|}{ Unilateral spinal } \\
\hline $47(6,9 \%)$ & $2(4.3 \%)$ & 0.798 \\
\hline \multicolumn{3}{|l|}{${ }^{\mathrm{b}} \mathrm{CSE}$} \\
\hline $10(1,4 \%)$ & 0 & - \\
\hline \multicolumn{3}{|l|}{ CPNB } \\
\hline $29(4,3 \%)$ & $1(3.4 \%)$ & - \\
\hline
\end{tabular}

in elderly patients) between age and time to surgery ( $r=0.238$; $\mathrm{p}<0.01$ ) (Figure 2).

\section{DISCUSSION}

The aim of this study was to evaluate the effects of time to surgery and anesthesia technique performed during the surgical treatment of hip fracture patients on in-hospital mortality and LOS. It was found out that the in-hospital mortality rates and LOS of the patients who had surgical delay for more than 48 hours were significantly higher than the patients who had surgery within 48 hours.

Guidelines point out the favorable effects of early surgical repair of the fractured hip on patient mortality in the literature. The Scottish Intercollegiate Guidelines Network suggest that the surgery should be performed as soon as possible, within safe operating hours, from the admission in medically fit patients, in order to reduce the postoperative mortality (15). Likewise, The British Orthopedic Association guidelines indicate that surgical repair should not be delayed for more than 48 hours from admission unless the patient has clearly reversible medical conditions (16).

Many studies show that a prolonged surgical delay significantly increases the mortality $(7,14,17-21)$. McGuire et al. (18) reported increased mortality rates within 30 days in hip fracture patients who had surgical delay for more than 48 hours. In a recent study, Dailiana et al. (19) pointed out a significant association between delayed surgery ( $>48$ hours) and increased in-hospital mortality. On the other hand, many studies show that early surgery (performed within 48 hours) does not reduce mortality $(14,22,23)$. High mortality rates in these studies are associated with patient's comorbidities and poor medical conditions, but not with surgery time. In a review of 52 published studies involving 291.413 patients, it was found that none of the included studies demonstrated a causal relationship between surgical delay and mortality rates (13). Another comprehensive study including 2.660 patients not surprisingly indicates that delayed surgery patients with comorbidities have 2.5 times more risk of death compared to the delayed surgery patients without comorbidities within thirty

Table 4. Age, LOS and Timing of the operation correlation

\begin{tabular}{|l|l|l|} 
& Age (years) & \\
\hline & $\mathbf{r}$ & $\mathbf{p}$ \\
\hline aLenght of hospital stay & 0.324 & $0.001^{* *}$ \\
\hline aTiming of the operation (day) & 0.238 & $0.001^{* \star}$ \\
\hline a: Spearman's correlation analysis, ${ }^{* *} p<0.01$ & & \\
\hline
\end{tabular}

\section{Table 3. Evaluation of the LOS according to different anesthesia techniques}

\begin{tabular}{|c|c|c|c|c|c|c|c|}
\hline & & \multicolumn{6}{|c|}{${ }^{\mathrm{a}}$ Anesthesia technique } \\
\hline & & General & Bilateral spinal & Unilateral spinal & ${ }^{c} \mathrm{CSE}$ & dPNB & $\mathrm{p}$ \\
\hline $\begin{array}{l}\text { 'LOS } \\
\text { (day) }\end{array}$ & $\begin{array}{l}\text { Mean } \pm \text { SD } \\
\text { Median }\end{array}$ & $\begin{array}{l}17.11 \pm 10.75 \\
15.0\end{array}$ & $\begin{array}{l}15.27 \pm 10.36 \\
14.0\end{array}$ & $\begin{array}{l}13.25 \pm 5.59 \\
13.0\end{array}$ & $\begin{array}{l}16.20 \pm 9.31 \\
11.5\end{array}$ & $\begin{array}{l}11.31 \pm 5.76 \\
10.0\end{array}$ & $0.001 * *$ \\
\hline
\end{tabular}




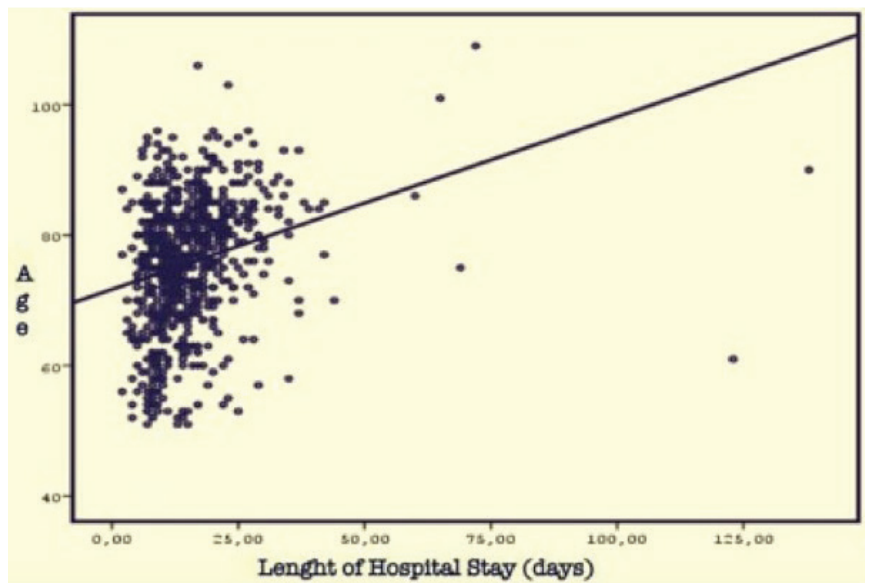

Figure 1. Length of hospital stay (days)

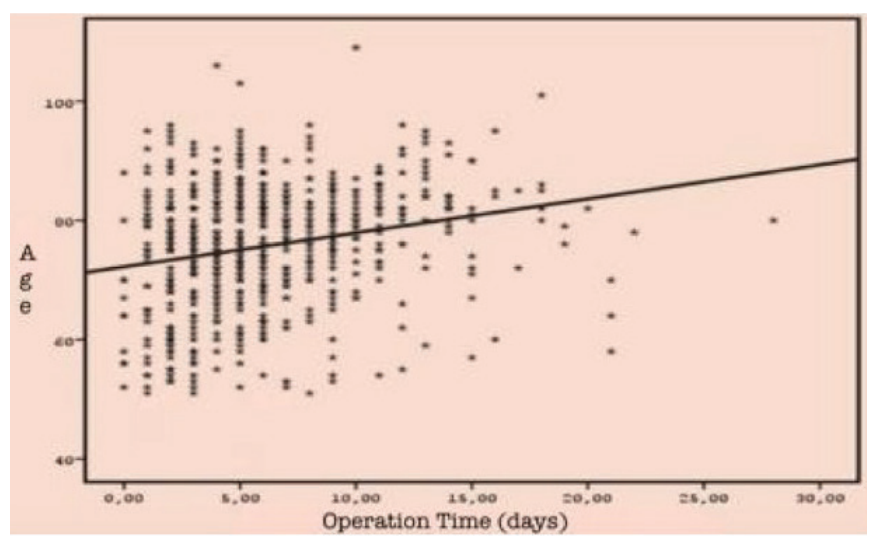

Figure 2. Operation time (days)

days after the surgery. They also showed the delayed surgery up to four days did not increase the mortality of the patients who were fit for the surgery; however, a delay of more than four days significantly increased mortality in these patients (24).

The in-hospital mortality rate in the present study was $5.1 \%(n=36)$, concordant with the literature. In a study including 4.633 patients, Novack et al. (25) reported the in-hospital mortality and 30-day mortality rates as $4,5 \%$ and $6,1 \%$, respectively. Anwar et al. (26) reported the in-hospital, 30-day and total mortality rates of the surgically treated hip fracture patients as $5.6 \%, 10.6 \%$, and $16.3 \%$, respectively. Also, the in-hospital mortality rate of men was $11.5 \%$ while that of women was $4.3 \%, 30$-day and total mortality rates were $4.6 \%$ and $17.9 \%$, respectively, in a recent study performed in Greece (19).

The results of the present study demonstrated that LOS was significantly shorter in patients who had surgery within 48 hours. There are many studies suggesting that the LOS could be improved by shortening the waiting time for surgery $(20,27-31)$. In a recent study conducted in USA, preoperative time to surgery, anesthesia type and procedure type were shown to be three modifiable risk factors for increased LOS (27). Bergeron et al. (28) reported that the delayed surgery lengthens the hospitalizations in their study involving 977 patients. These results might be associated with reduced complications caused by prolonged bed rest and immobilization before surgery, which may lengthen the hospitalization and even increase the mortality rates. However, this relationship is not universally supported, there are also studies suggesting that there is no significant effect of early surgery on LOS (32-34).

Different anesthesia techniques were performed during the surgical fixation of the patients. $48.1 \%$ of the patients received general anesthesia while 51.9\% received regional anesthesia (spinal anesthesia $46.2 \%$, peripheral nerve block $4.2 \%$ and CSE anesthesia 1.5\%). Many studies pointed out the association between non-general anesthesia techniques and reduced mortality recently (21,31-33). Rodgers et al. (31) demonstrated that neuroaxial anesthesia techniques reduce postoperative mortality. Luger et al. (32) conducted a wide study including 18.715 patients and reported that the spinal anesthesia reduced early mortality rates and complications like deep venous thrombosis and acute postoperative confusion in geriatric hip fracture patients. However, there are many studies with conflicting results (3436). O'Hara et al. (34) could not reveal the regional anesthesia technique's positive impact on mortality compared to general anesthesia in their retrospective study including 9425 patients. Le-Wendling et al. (35) reported that there was no difference in in- hospital mortality, postoperative mortality, treatment costs and re-hospitalization when the general anesthesia and regional anesthesia techniques were compared in geriatric hip fracture population. In a retrospective cohort study including 73.284 adults undergoing hip fracture surgery, mortality risk did not differ significantly by anesthesia type (36). Also, in a recent study performed in our country, surgically treated 187 hip fracture patients' 30 -day mortality rates according to anesthesia techniques were reported as follows: general anesthesia group $1.4 \%$, spinal anesthesia group $5.9 \%$, and epidural group $5.8 \%$, in which there was no superiority shown for the techniques on each other (37). In contrary with all these results, the in-hospital mortality rates of the regional anesthesia group in the present study were significantly lower when compared to the general anesthesia group while there were no significant differences between the regional techniques, themselves. These results might be related to the choice of regional techniques for less invasive surgery like CRIF or the preference general anesthesia for high-risk patients rather than regional techniques.

There are many studies suggesting that there is no relationship between the anesthesia technique and $\operatorname{LOS}(31,38)$. In a study of 217 patients performed by Liu et al. (38), no differences were shown in mortality rates and LOS, when the general anesthesia and peripheral nerve blockage techniques were compared. Also, in a recent study conducted in USA, no superiority was shown for regional techniques to general anesthesia when compared in terms of mortality. On the other hand, LOS of regional anesthesia group was found modestly shorter (39). However, Basques et al. (27) pointed out the non-general anesthesia clinically significantly 
increased LOS relation in their recent study including 8.434 surgically treated hip fracture patients. In the present study, we observed significant differences in LOS when the anesthesia techniques were compared. The general anesthesia group had significantly longer hospitalizations when compared to the regional anesthesia groups, and the neuroaxial anesthesia group had significantly longer hospitalizations when compared to the peripheral nerve block group. Lower mortality rates and shorter LOS might be related to known reduced complications of regional anesthesia techniques and earlier ambulation of the patients in this group.

\section{CONCLUSION}

It was concluded that hip fracture surgery should be performed as soon as the patient is medically stabilized within 48 hours with regional anesthesia techniques in order to achieve better results of early outcomes like in-hospital mortality and LOS.

Ethics Committee Approval: Ethical Committee approval was obtained from Gaziosmanpaşa Taksim Training and Research Hospital (approval number: 2011/809-569)

Informed Consent: This is a retrospective research; therefore, informed consent was not obtained from the patients.

Peer-review: Externally peer-reviewed.

Author Contributions: Concept - G.K., K.K.; Design - K.K., M.Ç.K.; Supervision - K.P., M.B.; Resources - K.P., G.K., M.B.; Materials - G.K.; Data Collection or Processing - G.K.; Analysis or Interpretation - M.B.; Literature Search - G.K.; Writing - G.K., M.B.; Critical Review - K.P., M.B., K.K.

Conflict of Interest: The authors have no conflict of interest to declare.

Financial Disclosure: The authors declared that this study has received no financial support.

\section{REFERENCES}

1. Meessen JM, Pisani S, Gambino ML, Bonarrigo D, Van Schoor NM, Fozzato $\mathrm{S}$ et al. Assessment of mortality risk in elderly patients after proximal femoral fracture. Orthopedics 2014; 37: 194-200

2. Pillai $A$, Eranki V, Shenoy R, Hadidi M. Age related incidence and early outcomes of hip fractures: a prospective cohort study of 1177 patients. J Orthop Surg Res 2011; 24: 6:5.

3. Ekström W, Miedel R, Ponzer S, Hedström M, Samnegård E, Tidermark J. Quality of life after a stable trochanteric fracture - a prospective cohort study on 148 patients. J Orthop Trauma 2009; 23: 39-4.

4. Shiga T, Tsuji Y, Fujioka M, Kubo T. Risk factors for hip fracture in Japanese elderly women with osteoporosis: Applicability of biochemical markers in bone turnover. Geriatr Gerontol Int 2009; 9: 69-4.

5. Şenol Y, Akdeniz M. Yaşlılık ve Koruyucu Tıp. GeroFam 2010; 1: 49-68.

6. Diamantopoulos AP, Hoff M, Hochberg M, Haugeberg G. Predictors of short and long-term mortality in males and females with hip fracture- a prospective observational cohort study. PLoSOne 2013; 8: e78169

7. Shiga T, Wajima Z, Ohe Y. Is operative delay associated with increased mortality of hip fracture patients? Systematic review, meta-analysis, and meta-regression. Can J Anaesth 2008; 55: 146-54.

8. González-Rozas M, Pérez-Castrillón JL, González-Sagrado M, RuizMambrilla M, García- Alonso M. Risk of mortality and predisposing factors after osteoporotic hip fracture: a one-year follow-up study. Aging Clin Exp Res 2012; 24: 181-7.

9. Grønskag AB, Romundstad P, Forsmo S, Langhammer A, Schei B. Excess mortality after hip fracture among elderly women in Norway: the HUNT study. Osteoporos Int 2012; 23: 1807-11.

10. Auffarth A, Resch H, Lederer S, Karpik S, Hitzl W, Bogner R et al. Does the choice of approach for hip hemiarthroplasty in geriatric patients significantly influence early postoperative outcomes? A randomizedcontrolled trial comparing the modified smith- petersen and hardinge approaches. J Trauma 2011; 70: 1257-62.

11. Miller AG, Bercik MJ, Ong A. Nonagenarian hip fracture: Treatment and complications:J Trauma Acute Care Surg. 2012; 72: 1411-5.

12. Ayoung-Chee P, Mclntyre L, Ebel BE, Mack CD, McCormick W, Maier RV. Long-term outcomes of ground-level falls in the elderly: J Trauma Acute Care Surg 2014; 76: 498-503.

13. Khan SK, Kalra S, Khanna A, Thiruvengada MM, Parker MJ. Timing of surgery for hip fractures: A systematic review of 52 published studies involving 291,413 patients. Injury 2009; 40: 692-7.

14. Orosz GM, Magaziner J, Hannan EL, Morrison RS, Koval K, Gilbrt M et al. Association of timing of surgery for hip fracture and patient outcome. JAMA. 2004; 291: 1738-43.

15. Scottish Intercollegiate Guidelines Network. prevention and management of hip fracture inolder people: A national clinical guideline. Edinburgh, UK: Scottish Intercollegiate Guidelines Network; 2002.

16. British Orthopaedic Association Standarts for Trauma (BOAST): Hip fracture in the older person. September 2007.

17. Simunovic N, Devereaux PJ, Sprague S, Guyatt GH, Schemitsch E, Debeer $\mathrm{J}$ et al. Effect of early surgery after hip fracture on mortality and complications: systematic review and meta-analysis. CMAJ 2010; 182: 1609-16.

18. McGuire KJ, Bernstein J, Polsky D, Silber JH. Delays until surgery after hip fracture increases mortality. Clin Orthop Relat Res 2004; 428: 294-301.

19. Dailiana Z, Papakostidou I, Varitimidis S, Michalitsis SG, Veloni A, Malizos $\mathrm{KN}$. Surgical treatment of hip fractures: factors influencing mortality. Hippokratia 2013; 17: 252-7.

20. Verbeek DOF, Ponsen KJ, Goslings JC, Heetveld MJ. Effect of surgical delay on outcome in hip fracture patients: a retrospective multivariate analysis of 192 patients. Int Orthop 2008; 32: 13-8.

21. Kesmezacar H, Ayhan E, Unlu MC, Seker A, Karaca S. Predictors of mortality in elderly patients with an intertrochanteric or a femoral neck fracture. J Trauma 2010; 68: 153-8.

22. Vidán MT, Sánchez E, Gracia Y, Marañón E, Vaquero J, Serra JA. Causes and effects of surgical delay in patients with hip fracture: a cohort study. Ann Intern Med. 2011; 155: 226-33.

23. Librero J, Peiró S, Leutscher E, Merlo J, Bernal-Delgado E, Ridao $M$ et al. Timing of surgery for hip fracture and in-hospital mortality: a retrospective population-based cohort study in the Spanish National Health System. BMC Health Serv Res 2012; 12: 15.

24. Moran CG, Wenn RT, Sikand M, Taylor AM. Early mortality after hip fracture: is delay before surgery important? J Bone Joint Surg Am 2005; 87: 483-9.

25. Novack $V$, Jotkowitz $A$, Etzion $O$, Porath $A$. Does delay in surgery after hip fracture lead to worse outcomes? A multicenter Survey. Int J Qual Health Care 2007: 19: 170-6.

26. Anwar W, Rahman N, Khan A, Kashif S, Siraj M, labal MJ et al. Relationship of preoperative surgical delay to mortality after hip fracture in elderly patients. Journal of Surgery Pakistan (International) 17 2012; 1: 20-3.

27. Basques BA, Bohl DD, Golinvaux NS, Leslie MP, Baumgaertner MR, Grauer JN. Postoperative length of stay and thirty-day readmission following geriatric hip fracture: ann analysis of 8,434 patients. J Orthop Trauma 2014.

28. Bergeron E, Lavoie A, Moore L, Bamvita JM, Ratte S, Gravel C, et al. Is the delay to surgery for isolated hip fracture predictive of outcome in efficient systems? J Trauma 2006; 60: 753-7.

29. Ho V, Hamilton BH, Roos LL. Multiple approaches to assessing the effects of delays for hip fracture patients in the United States and Canada. Health Serv Res 2000; 34: 1499-518.

30. Hamilton $\mathrm{BH}$, Hamilton $\mathrm{VH}$, Mayo NE. What are the costs of queuing for hip fracture surgery in Canada? J Health Econ 1996; 15: 161-85.

31. Rodgers A, Walker N, Schug S, McKee A, Kehlet H, van Zundert A, et al. Reduction of postoperative mortality and morbidity with epidural or spinal anaesthesia: results from overview of randomised trials. BMJ 2000; 321 (7275): 1493

32. Luger TJ, Kammerlander C, Gosch M, Luger MF, Kammerlander-Knauer $U$, Roth $T$, et al. Neuroaxial versus general anaesthesia in geriatric 
patients for hip fracture surgery: does it matter? Osteoporos Int. 2010; 21(Suppl 4): 555-72.

33. Karaca S, Ayhan E, Kesmezacar H, Uysal O. Hip Fracture Mortality: Is It Affected by Anesthesia Techniques? Anesthesiology Research and Practice 2012: 708754.

34. O'Hara DA, Duff A, Berlin JA, Poses RM, Lawrence VA, Huber EC, et al. The effect of anesthetic technique on postoperative outcomes in hip fracture repair. Anesthesiology 2000; 92: 947-57.

35. Le-Wendling L, Bihorac A, Baslanti TO, Lucas S, Sadasivan K, Wendling A et al. Regional anesthesia as compared with general anesthesia for surgery in geriatric patients with hip fracture: does it decrease morbidity, mortality, and health care costs? Results of a single-centered study. Pain Med 2012; 13: 948-56.

36. Patorno E, Neuman MD, Schneeweiss S, Mogun H, Bateman BT. Comparative safety of anesthetic type for hip fracture surgery in adults: retrospective cohort study. BMJ. 2014; 348: g4022.

37. Şahin SH, Heybeli N, Çolak A, Arar C, Alan K, Copuroglu C, et al. Comparison of different anesthetic techniques on postoperative outcomes in elderly patients with hip fracture. TurkiyeKlinikleri J Med Sci 2012; 32: 623-9.

38. Liu JL, Wang XL, Gong MW, Mai HX, Pei SJ, Yuan WX, et al. Comparative outcomes of peripheral nerve blocks versus general anesthesia for hip fractures in geriatric Chinese patients.Patient Prefer Adherence 2014; 8 : 651-9.

39. Neuman MD, Rosenbaum PR, Ludwig JM, Zubizarreta JR, Silber JH. Anesthesia Technique, Mortality, and Length of Stay After Hip Fracture Surgery. JAMA 2014; 311: 2508-17. 